\title{
Evolution and market behavior in economics and finance: introduction to the special issue
}

\author{
Giulio Bottazzi • Pietro Dindo
}

Published online: 15 May 2013

(C) Springer-Verlag Berlin Heidelberg 2013

The articles contributing to this special issue were originally presented at a Workshop held in September 2009 at the Sant'Anna School of Advanced Studies in Pisa and titled "Evolution and Market Behavior in Economics and Finance". The aim of the workshop was to gather scholars working on the application of evolutionary theory concepts, such as selection, mutation and replication, to economics, in particular, to the understanding of the selection operated by markets, and to discuss ideas for future research in this area. The analysis of market selection and the characterization of the emerging market properties, such as allocative and informational efficiency, from an "evolutionary" perspective, have received an increasing attention in the last years. The typical evolutionary model studies the exchange of real or financial assets by heterogeneous boundedly rational agents, using the evolution of cumulated wealth or payoff to determine survival and dominance of specific strategies or behaviors and, consequently, the aggregate economic dynamics. The central question is indeed which types of expectations, information sets, preferences, learning models are rewarded in the long-run and their effect on market properties.

More generally, by considering an a-priori large ecology of behaviors, evolutionary market models are good candidates to question the dominating neoclassical paradigm embodied by the use of households and firms characterized by "substantive rationality" (Simon 1976), that is, optimizing with respect to a well defined

We acknowledge financial support from the Institute for New Economic Thinking, INET inaugural grant \#220 and the European Commission 6th FP Project DIME (Contract CIT3-CT-2005-513396). All usual disclaimers apply.

\section{G. Bottazzi $(\bowtie)$}

Istituto di Economia, Scuola Superiore Sant'Anna, Piazza Martiri della Libertà 33, 56127 Pisa, Italy

e-mail: g.bottazzi@sssup.it

P. Dindo $(\bowtie)$

Dipartimento di Economia e Management, Università di Pisa, Via C.Ridolfi 10, 56124 Pisa, Italy

e-mail: p.dindo@ec.unipi.it 
structure of preferences and with rational expectations. Despite most economists, both theoretical and applied, being aware of the importance of departing from this restrictive view of human behavior, the common wisdom in the economic profession still remains that the rewarding mechanism intrinsic in competitive economies is able to select for rational economic actors in such a way that the resulting aggregate dynamics becomes virtually identical to that obtained postulating substantive rational households and firms. The general underlying idea, which goes back to Friedman (1953) and, partly, to Alchian (1950), and which is known as the "as if" argument or as the Efficient Market Hypothesis (EMH), is that agents who are not rational would disappear from the market. Since rationality implies higher income and profits, all the resources will flow into the hands of rational households and firms. As a result, market selection and, through it, the re-allocation of resources, are considered to have settled at the rest point where only rational actors survive. ${ }^{1}$ Moreover, due to the technical difficulties of computing equilibria in rational expectations models with heterogeneous agents, most authors just assume heterogeneity away and model each sector of the economy (production, consumption, investment,... ) as populated by a single representative agent. In this way, paradoxically, market institutions disappear from economic models, as their allocative and informational roles are completely reabsorbed in the maximization problem of a single planner.

Given the widespread reliance of economic modeling on the EMH, exploring the limits of its validity constitutes a particularly relevant, albeit extremely challenging, theoretical and empirical question. The major objective of this research program, well represented by the contributions gathered in the present issue, is precisely to investigate when the EMH is legitimate and when, instead, markets and their selection properties contribute to a determination of the aggregate economic dynamics. In the latter case, one also wants to inquire as to the way in which economic policies can be improved in the light of the inconclusive outcomes of market selection, possibly induced by imperfections such as market incompleteness, informational asymmetries, externalities, or rigidities. In other words, models postulating rational households and firms can be considered to possess some economic content only if the convergence to rational behavior can be proven true under the specific set of assumptions presumed to describe the reality of economic interactions. Otherwise, the explicit dynamics of the market selection process should be taken into account, both in the positive and normative domains.

In focusing on the role of market selection, the approach put forward by the contributions of this special issue complements the large evolutionary literature stemming from Nelson and Winter (1982) and known as Post-Schumpeterian (Dosi and Winter 2000), or Neo-Schumpeterian (Witt 2008). This literature is mostly devoted to the study of the economic consequences, and premises, of innovation and technical change and their relations with industrial dynamics and macroeconomic growth. As such, it looks at the selection issue from a different angle. In the contributions of this issue, selection operates exclusively on the exchange domain, thus "choosing" among demands that interact in allocations mechanisms, such as

\footnotetext{
${ }^{1}$ Interestingly, the global stability of the ensuing equilibria is generally not disputed.
} 
markets or auctions, mostly through a relative wealth dynamics. In Neo(Post)Schumpeterian contributions, conversely, selection operates on the production domain, thus "choosing" technologies and routines, the fitness of which is technically appraised, typically by the use of some sort of cost function, in a context where markets operate in an ideal way. ${ }^{2}$ Indeed, in introducing the Neo-Schumpeterian view to the readers of this Journal, Dosi and Nelson (1994) write "Cannot one argue that, if competitive forces are strong, firms that are not as efficient as the best firms may be forced out of business? Perhaps one can. But note that the standard here is defined by the most efficient existing firms, not the efficiency that is theoretically possible. And that benchmark level of efficiency may be determined by the actual learning processes that are operative and how far they have proceeded." [p.159]. It is clear that the authors' concern is more on the exploration of the space of technological or organizational opportunities rather than on the ability of competitive markets to redistribute resources to the (relatively) most efficient firm. Being aware that a fully-fledged model should entail both dimensions, and maybe their interaction as suggested in Dosi and Winter (2000), we view the explicit characterization and the analysis of the market selection dynamics as an essential contribution to the development of a successful evolutionary theory of economic phenomena.

Concerning the theoretical exploration of the market selection dynamics, the point of departure of many recent contributions can be traced back to the seminal paper by Blume and Easley (1992). ${ }^{3}$ They study the relative wealth dynamics among different investors repeatedly exchanging Arrow securities in a temporary equilibrium framework. Trading occurs because agents have different beliefs on the likelihood that a security will pay its dividend and/or different risk preferences. They find that market selection works in that there exists an investment rule that dominates against any other rule and drives asset prices to their correct values. However, they also construct examples where, in absence of the global dominating rule, market selection does not work and leads to asset miss-pricing, showing that the EMH deserves further investigation.

The first two contributions to the present issue, by Fano, LiCalzi, and Pellizzari, and by Anufriev, Arifovic, Ledyard, and Panchenko investigate selection and the resulting evolution of trading strategies in auction markets.

Fano et al. (2013) investigate the emergence of strategic behavior, modeled as a learning process driven by the genetic algorithm, in double auctions comparing cases in which orders are cleared simultaneously or asynchronously. The first main finding is that, provided that the number of agents is large, the competitive outcome arises under both market architectures. They point out that this is a manifestation of the general principle that, when the competitive pressure increases, it dampens individual incentives to search for a better price than the competitive one. The second important

\footnotetext{
${ }^{2}$ Inside the Neo(Post)-Schumpeterian literature, the allocative function of the market is often modeled as a black box, for instance by assuming a productivity-driven selection fed by an exogenous aggregate demand function, along the lines of the early (Winter 1971), or, similarly to what is done in evolutionary game theory (Sandholm 2009), by postulating some "population dynamics" not explicitly mediated by any market interaction [see Metcalfe (2008)]. Among the few exceptions, see Winter et al. (2003).

${ }^{3}$ Both the title of the workshop and of this special issue may be seen as an explicit reference to that paper.
} 
result is that, far from the large $n$ competitive outcome, market architecture plays a crucial role in deciding what strategic behavior is going to emerge. Under simultaneous order-clearing, increasing the competitive pressure makes marginal traders act as price takers who make offers equal to their evaluations/costs. Under asynchronous order-clearing, increasing the competitive pressure induces the intramarginal traders to act as price makers and make offers equal to the competitive price.

In a similar context, Anufriev et al. (2013) explore the way in which specific aspects of market transparency and agents' behavior affect market allocative efficiency. The central question is whether learning with and without information about other participants actions improves market efficiency. The learning is modeled through the Individual Evolutionary Learning (IEL) algorithm of Arifovic and Ledyard (2011), which incorporates both experimentation and selection with reinforcement. The first result is that, both with closed and opened order books, the IEL leads to a substantially higher efficiency than under Zero Intelligent trading. More importantly, Anufriev et al. show that the remaining sources of inefficiency are different in the two cases. Traders learn to submit their own valuations/costs under the closed book treatment, while the previously observed trading price dominates under the open book treatment. These individual differences result in differences at the aggregate level: higher price volatility and over-trading under the closed book relatively to the open book treatment. Their model predicts that market volatility should decrease as a result of higher transparency.

The following three papers, by Hauser and Kaempff, by Chiarella, Dieci, and He, and by Bottazzi and Dindo, look specifically at the exchange of financial assets.

Hauser and Kaempff (2013) investigate trading strategy selection and the resulting informational efficiency in an asset market with heterogeneously informed agents. Different information sets are nested one into the other and can thus be clearly ranked in levels. Within the same information level, a genetic algorithm is used to optimize agents' trading strategies. As prices may get distorted when several agents make coordinated trading decisions, strategies selected by the genetic programming can be characterized as information-based strategies that ignore the subset of information also available to less informed agents. The result is that no single strategy works well for all levels of information and the fundamental strategy of discounting future dividends is dominant only for agents with the highest degree of information. Less well-informed agents instead apply a rich diversity of strategies which, by minimizing their price impact, protects them from being exploited by insiders and leads to a high degree of informational efficiency.

Chiarella et al. (2013) consider the impact of market selection in the context of a stylized financial market and they do so with an empirical focus. They set up a dynamic equilibrium model of a financial market with two types of boundedly rational investors, fundamentalists and trend followers, whose portfolio choices are derived by one-period mean-variance optimization, and use it to develop an explicit dynamic CAPM relation between expected equilibrium returns and time-varying betas. Whereas most of the literature on time varying beta is motivated by econometric estimation using various latent strategies, they are able to model the stochastic dynamics of betas as due to agents' interaction. They show that, independently of the fundamentals of the economy, there is a systematic change in asset prices, returns, 
and time varying betas when investors change their behavior as captured by the trend extrapolation of the chartists, the mean-reversion of the fundamentalists, and the strength of the noise traders. Moreover, they show that the commonly used rolling window estimates of time varying beta coefficients are connected to, but may not be consistent with, the ex-ante betas implied by the equilibrium model.

Bottazzi and Dindo (2013) build on the same framework of Blume and Easley (1992) and confirm that the EMH does not generally hold for "evolutionary" financial markets. They consider a simple market of two Arrow securities, traded by heterogeneous investors, which they are able to investigate analytically. In particular, they characterize the long-run wealth and prices dynamics for any given pair of investment rules coming from the myopic optimization of a Constant Relative Risk Aversion utility. Their analysis delivers both a good and a bad message. The good message is that, when traders invest constant fractions of wealth in each asset and have equal consumption rates, markets are indeed informationally efficient: on average the best informed agent is rewarded and asset prices eventually reflect this information. However, and this is the bad message, when asset demands are more general, markets might behave sub-optimally: asymptotic prices depend on preferences and beliefs of the whole ecology of traders and do not, in general, reflect the best available information. In the paper it is also argued that these failures may be connected with those occurring the context of selection of profit maximizing firms and advanced by the Neo-Schumpeterian school (see in particular Nelson and Winter 2002), namely variety - selection operates exclusively on the existing competing rules, so that if the optimal rule is not trading in the market, it cannot possible be selected; behavioral continuity - a rule that is successful in period $t$ is not necessarily successful in period $t+1$, when market conditions may have changed; limited path-dependence - the fact that there can be transient phases where markets dynamics eliminates good rules; and profit-induced growth - even if a rule is earning wealth, it is not granted that this wealth is in fact used to grow.

The closing paper, by Anufriev, Hommes, and Philipse, investigates the evolutionary selection of expectations in positive and negative feedback markets. Anufriev et al. (2013) analyze the experimental results of markets with negative and positive feedbacks presented in Heemeijer et al. (2009), where it is shown that prices converge to the fundamental level in a negative feedback environment but fail to do so under positive feedback. They put forward an explanation based on a parsimonious model of evolutionary switching between adaptive and trend heuristics. Market simulations show that, in the negative feedback case, the adaptive heuristics dominates and, consistently with the experiment, strong oscillations in the first periods are followed by quick convergence towards the equilibrium price. In the positive feedback case instead, a trend-following heuristics dominates and, as in the experiments, prices exhibit persistent deviations from the equilibrium price and slow oscillations.

In preparing this special issue we have benefited from interacting with several people. First of all, we would like to thank the participants to the workshop for stimulating discussions: Mikhail Anufriev, Larry Blume, Fulvio Corsi, Roberto Dieci, Rémi Dorat, Giovanni Dosi, David Easley, Igor Evstigneev, Doyne Farmer, Edoardo Gallo, Laura Gardini, Tony He, Cars Hommes, Bob Kaempff, Alan Kirman, Marco LiCalzi, Matteo Marsili, Paolo Pin, Klaus Schenk-Hoppé, Fabio Tramontana, 
and Stefano Marmi, who also helped us in taking part to the workshop Scientific Committee. We are grateful to Uwe Cantner, editor of this Journal, for having decided to devote a special issue to this topic, and for having trusted us as guest editors. We thank him also for having acted as editor for our manuscript. A special thanks goes to the authors, who decided to submit their contributions for publication into this special issue, and to the referees, who helped to select the contributions to be included and to improve their overall quality. It is mostly their joint effort that made this endeavor possible.

\section{References}

Alchian A (1950) Uncertainty, evolution, and economic theory. J Polit Econ 58:211-221

Anufriev M, Arifovic J, Ledyard J, Panchenko V (2013) Efficiency of continuous double auctions with full or limited information. J Evol Econ. doi:10.1007/s00191-011-0230-8

Anufriev M, Hommes C, Philipse R (2013) Evolutionary selection of expectations in positive and negative feedback markets. J Evol Econ. doi:10.1007/s00191-011-0242-4

Arifovic J, Ledyard J (2011) A behavioral model for mechanism design: individual evolutionary learning. J Econ Behav Organ 78(3):374-395

Blume L, Easley D (1992) Evolution and market behavior. J Econ Theory 58:9-40

Bottazzi G, Dindo P (2013) Selection in asset markets: the good, the bad, and the unknown. J Evol Econ. doi:10.1007/s00191-013-0318-4

Chiarella C, Dieci R, He X-Z (2013) Time-varying beta: a boundedly rational equilibrium approach. J Evol Econ. doi:10.1007/s00191-011-0233-5

Dosi G, Nelson R (1994) An introduction to evolutionary theories in economics. J Evol Econ 4:153-172

Dosi G, Winter S (2000) Interpreting economic change: evolution, structures and games. LEM Working Paper 2000-08, Sant'Anna School of Advanced Studies

Fano S, LiCalzi M, Pellizzari P (2013) Convergence of outcomes and evolution of strategic behavior in double auctions. doi:10.1007/s00191-011-0226-4

Friedman M (1953) Essays in Positive Economics. University of Chicago Press, Chicago

Hauser F, Kaempff B (2013) Evolution of trading strategies in a market with heterogeneous agents. J Evol Econ. doi:10.1007/s00191-011-0232-6

Heemeijer P, Hommes C, Sonnemans J, Tuinstra J, Price stability and volatility in markets with positive and negative feedback: an experimental investigation (2009). J Econ Dyn Control 33:1052-1072

Metcalfe JS (2008) Accounting for economic evolution: Fitness and the population method. J Bioecon 10(1):23-49

Nelson R., Winter S (1982) An evolutionary theory of economic change. Harvard University Press, Cambridge

Nelson R, Winter S (2002) Evolutionary theorizing in economics. J Econ Perspect 16:23-46

Sandholm WH (2009). In: Meyers RA (ed) Encyclopedia of complexity and systems science. Springer, Heidelberg

Simon H. (1976). In: Latsis S. (ed) Method and appraisal in economics. Cambridge University Press, Cambridge

Winter S (1971) Satisficing, selection, and the innovating remnant. Q J Econ 85:237-261

Winter S, Kaniovski Y, Dosi G (2003) A baseline model of industry evolution. J Evol Econ 13(4):355-383

Witt U (2008) What is specific about evolutionary economics? J Evol Econ 18:547-575 